\title{
Culturas urbanas e espaços públicos: Sobre as cidades e a emergência de um novo paradigma sociológico
}

Urban Cultures and Public Spaces: On Cities and the Emergence of a New Sociological Paradigm

Cultures urbaines et espaces publics: Sur les villes et l'émergence d'un nouveau paradigme sociologique

\section{Carlos Fortuna}

\section{OpenEdition}

\section{Journals}

Edição electrónica

URL: http://journals.openedition.org/rccs/1272

DOI: $10.4000 /$ rccs. 1272

ISSN: 2182-7435

\section{Editora}

Centro de Estudos Sociais da Universidade de Coimbra

Edição impressa

Data de publição: 1 Outubro 2002

Paginação: 123-148

ISSN: 0254-1106

\section{Refêrencia eletrónica}

Carlos Fortuna, «Culturas urbanas e espaços públicos: Sobre as cidades e a emergência de um novo paradigma sociológico », Revista Crítica de Ciências Sociais [Online], 63 | 2002, colocado online no dia

01 outubro 2012, criado a 19 abril 2019. URL : http://journals.openedition.org/rccs/1272 ; DOI :

$10.4000 /$ rccs. 1272 


\section{CARLOS FORTUNA}

Faculdade de Economia da Universidade de Coimbra e Centro de Estudos Sociais

\section{Culturas urbanas e espaços públicos: Sobre as cidades e a emergência de um novo paradigma sociológico ${ }^{1}$}

O texto começa por perguntar se seremos capazes de construir mais e melhor cidade no futuro próximo. Implícito está o pressuposto de que a sociologia urbana, na sua versão clássica, não está em condições de oferecer indicações sobre como fazê-lo. Para tal, ela terá que repensar-se e que reformar os seus quadros teóricos e procedimentos analíticos. Para ilustrar esta necessidade, o texto percorre terrenos (zonas de intermediação) onde habitualmente apenas se vêem sinais de retracção dos espaços públicos e busca neles potenciais virtudes políticas em emergência.

\section{Introdução, ou sobre a sociologia das cidades}

A julgar pela análise demográfica prospectiva, dentro de uns cinquenta anos a população mundial a viver nas cidades deverá rondar os seis biliões, o que representa grosso modo o dobro da população urbana actual. Se juntarmos a isto a precariedade das condições de vida urbana oferecidas pelas cidades e grandes metrópoles de hoje, reconheceremos de imediato que, ao longo das próximas décadas, se torna absolutamente inevitável construir não apenas mais cidade, mas também melhor cidade. A questão central que se nos coloca é, desde logo, a de saber se seremos capazes de construir a cidade que imaginamos. Trata-se de uma questão compartilhada com outros, nomeadamente Richard Rogers (2001) ou Susan Fainstein (1999), que questionam a cidade do futuro, não tanto do ponto de vista técnico, apesar das limitações que imperam nos domínios da capacidade política e de liderança, dos recursos e do conhecimento necessários para construir mais cidade, mas, sobretudo, do ponto de vista sociocultural e da capacidade para conferir expressão prática ao amplo património de reflexão de que dispomos sobre o que poderá ser amanhã uma cidade melhor do que aquela que conhecemos hoje.

\footnotetext{
${ }^{1}$ Retomam-se neste texto alguns argumentos expandidos num outro ensaio - "As cidades do lado da cultura” - escrito em co-autoria com Augusto Santos Silva (Fortuna e Silva, 2001).
} 
O presente texto é apenas um modesto contributo para a questão que acabo de enunciar. ${ }^{2}$ Limito-me, na verdade, a equacionar alguns dos traços gerais da evolução da cidade ou, mais propriamente, da análise sociológica que sobre ela se produziu, para, de seguida, me referir a algumas dimensões socioculturais mais recentes que, à medida que se vão instituindo no cenário urbano, parecem requerer uma reflexão sociológica renovada sobre as cidades. Por outro lado, trata-se aqui de proceder ao registo de alguns aspectos que, vistos do ponto de vista do sociólogo, poderiam ser lidos como notas sobre algumas expressões actuais da vida e da cultura urbanas que condicionam de uma ou outra forma os ordenamentos urbanos das próximas décadas.

A afirmação moderna da cidade como entidade autónoma, política, económica, administrativa e cultural, é uma longa história de tensões e conflitualidades. Na cidade medieval e barroca, por exemplo, este quadro de tensões coloca a cidade em manifesta oposição àquilo que hoje designamos por "campo". "Os ares da cidade libertam", esse velho aforismo da Alemanha pré-moderna é elucidativo deste conflito, pois, nele, a cidade representa a liberdade e emancipação política e social a que aspiram os camponeses.

Esta oposição cidade-campo está presente nos estudos consagrados de Lewis Mumford (1961), Arnold Toynbee (1970), Fustel de Coulanges (1997) e Aidan Southall (1998) que, entre outros, se aventuram na mais profunda escatologia da urbanidade. Mas também Henri Pirenne (1973) ou Fernand Braudel (1984) mostram como a efervescência da economia e do comércio medievais ajudaram a forjar a cidade como centro nevrálgico da modernidade, à custa da economia agrícola e do mundo rural.

É desta "guerra” que a sociologia urbana clássica dá conta nos seus primórdios. Max Weber (1982) e Werner Sombart (1978), nomes sonantes da "Escola Alemã" fundadora desta tradição sociológica (Jonas, 1995), cuja perspectiva permanece fundamentalmente histórica, demonstram como o urbano se foi tornando hegemónico e sobrepujou o rural através da constituição daquilo a que o autor de Economia e sociedade chama o "urbanismo pleno" (Fortuna, 1997).

\footnotetext{
${ }^{2}$ Entre as referências que me parecem conter propostas e linhas de análise particularmente ricas para o reforço da investigação sociológica em torno desta preocupação, assinalo, particularmente, os trabalhos de Pais (1993, 1999), Baptista (1997), Esperança (1997), Silvano (1997), Sebastião (1998), José Luís Fernandes (1998), José Manuel Fernandes (1999), Costa (1999), Ferreira e Indovina (1999), Salgueiro (1999), Silva et al. (2000) e Lopes (2000). Para uma resenha de outros trabalhos, pode consultar-se a bibliografia fornecida no n. ${ }^{\circ} 1$ da recém-surgida publicação Cidades: Comunidades e Territórios.
} 
Ferdinand Tönnies, com o seu influente par Gemeinschaft/Gesellschaft, (Tönnies, 1972), ainda se deteve sobre este confronto. Contudo, poucos anos depois, o ensaio de Georg Simmel $A$ metrópole e a vida do espírito, (Simmel, 1997a), seria premonitório do modo como a sociologia viria a consagrar a cidade como domínio autónomo da investigação.

Como se sabe, a sociologia urbana de Simmel teve influência mais directa e imediata entre estudiosos americanos e, mais especificamente, entre destacados membros da Escola de Chicago. No decurso da primeira metade do século XX, quando ganharam destaque os estudos de ecologia urbana, as análises sobre a estrutura espacial da cidade e o conceito de sistema urbano, articulado com os de especialização funcional e de hierarquia urbana, fecha-se, em definitivo, a discussão em torno da autonomia da cidade e consagra-se o estatuto próprio e especializado do seu estudo. ${ }^{3}$

Após o interregno político e de produção académica europeia de entre guerras, a sociologia urbana ressurge na Europa, pela mão de Raymond Ledrut (1968), Henri Lefebvre (1968, 1974) e de Manuel Castells (1973, 1984), discípulo deste. Estes autores renovam profundamente o quadro de análise sociológica da cidade, ao dirigirem a investigação para a relação entre o ordenamento urbano e a estrutura social. A relação da cidade com os movimentos sociais e o papel do Estado ganha proeminência, sobretudo na obra de Castells, que, talvez por isso, recorde-se, funcionou como verdadeira "doutrina" quando o estudo da sociologia se desenvolveu em Portugal após 1974. O contributo de Lefebvre, como mostram hoje diversos estudos (maxime Shields, 1999), é bem mais sofisticado. O modo como este "marxista humanista" inscreve o espaço nas relações sociais, que aliás ecoa a própria "sociologia do espaço" de Simmel (1997b), não só resistiu mais duradouramente à usura do tempo como permanece uma referência incontornável para a compreensão da cidade actual e das suas dimensões socioculturais (A. T. Fernandes, 1999).

A partir desta rapidíssima síntese, podemos dar-nos conta, em traços muito largos, da situação em que a cidade, tanto a cidade reflectida pela/na teoria como a cidade da realidade vivida, permaneceu por longo tempo um universo social dependente, nomeadamente da vitalidade da economia agrária e da sociedade rural (Rémy e Voyé, 1994). Como era de esperar,

\footnotetext{
${ }^{3}$ É nesta época que, pela mão da sociologia urbana norte-americana, se estipula o princípio elementar de que as cidades não podem ser analisadas isoladamente; ao invés, a sua compreensão requer uma atenção muito particular aos fenómenos de interdependência urbana. O conceito de sistema urbano ganha destaque nos estudos sobre as cidades, que assim tendem a conjugar a análise dos elementos singulares (cidades), com os seus recursos e atributos (dimensão populacional, emprego, estrutura produtiva, etc.) e as relações estabelecidas entre uns e outros.
} 
também a análise sociológica permaneceu refém, por muito tempo, da história social. Com o advento da cidade da era industrial, à medida que a cidade se desvinculava do mundo rural, também a sociologia se afastava da análise histórica. Não estou certo de que tenha ganho maior nitidez de análise, mas, por certo, perdeu no tocante à profundidade de perspectiva.

O melhor exemplo que posso dar desta poderosa inscrição da contemporaneidade na análise da cidade retiro-o do acutilante relato sócio-etnográfico de Friedrich Engels sobre as condições da vida operária na Manchester vitoriana. Desse relato retenho apenas a descrição da estratégia de segregação da classe operária e da sua invisibilização. De acordo com Engels, em virtude da "curiosa configuração da cidade", era possível viver em Manchester anos a fio, ir e vir para o emprego, sem nunca se avistar um bairro operário (Engels, 1958: 54). ${ }^{4}$ A referência remete-nos para a fractura profunda da ordem política da cidade da era industrial, fundada no princípio da demarcação das desigualdades, das diferenças e das distâncias sociais. A cidade é agora eminentemente excludente: repele e subalterniza os grupos sociais vulneráveis que, para usar a fina ironia de Engels, "ofendem a frágil sensibilidade do olhar burguês".

Por outras palavras, diria que, com a era industrial, a "morte" do campo e a hegemonização do urbano precipitaram a sociologia para a análise da contemporaneidade vitoriosa da cidade. O contraponto simbólico desta "morte" do campo é a "morte" também simbólica de uma parte da cidade - a dos mais frágeis, pobres e incultos - às mãos da outra parte - a dos mais ricos, cultos e poderosos. Metaforicamente, dir-se-ia que a cidade substituiu o seu conflito com o campo e o rural pelo conflito consigo própria e que se instaurou na cidade moderna e industrial o conflito da cidade contra a "não"-cidade.

A Manchester de Engels, como arquétipo da cidade moderna e industrial, não é episódica nem epifenomenal. Com efeito, a leitura de The City of Quartz de Mike Davis (1990) sobre Los Angeles, escrita quase 150 anos

\footnotetext{
${ }^{4}$ Esta deliberada ocultação das classes operárias e das suas condições de vida constitui uma das principais justificações do processo de suburbanização que haveria de revelar-se o principal agente do crescimento futuro das cidades. Tal desenrolar inspirou uma vastíssima e aguerrida reflexão anti-urbana, alimentada não apenas pelos malefícios da industrialização e da monetarização das relações sociais, como no caso de Engels, mas principalmente pela moral burguesa que acusa a cidade de promover a degradação cívica e moral dos cidadãos, precarizar a sua condição física e intelectual e instigar a desordem, o vício e a doença (por exemplo, Stallybrass e White, 1986; Short, 1991). Em contraste com este pessimismo urbano, nas sociedades em que se tornara impossível oferecer o campo e a vida rural como alternativa mercê da maciça fuga para a cidade, os subúrbios eram frequentemente referidos como a solução mais segura, onde a família, a estabilidade e a comunidade de valores podiam desenvolver-se a coberto dos riscos da grande cidade (Stilgoe, 1988; Chaney, 1994).
} 
depois do surgimento da $A$ situação da classe operária em Inglaterra, é particularmente ilustrativa da continuidade histórica da "guerra" entre cidade e "não"-cidade. Se é isto que une Engels e Mike Davis, tomados como personificações de contextos temporais distantes entre si, interrogo-me sobre o que os separa e distancia.

Aquilo que separa a metrópole industrial e moderna da metrópole tardia e pós-moderna é um lapso de tempo e de transformações profundas que podem ser resumidos no seguinte conjunto de factores:

1. A incessante urbanização do mundo e o crescimento das cidades, a partir do centro para as margens, de que resulta a desvitalização recíproca tanto social como cultural de ambos os territórios;

2. O poder de intervenção e o monopólio de expertise de urbanistas e arquitectos para imporem um sistema de significação e de intencionalidade ao espaço urbano, à margem da participação pública e democrática dos não-especialistas;

3. A flexibilização pós-fordista, conjugada com o processo duplo de desindustrialização e reindustrialização, e os seus efeitos sobre a criação de espaços vazios no interior das cidades;

4. O desenvolvimento das tecnologias e as correspondentes compressão espácio-temporal e desterritorialização dos processos produtivos e comunicacionais;

5. A cultura da velocidade (e da mobilidade) e a transfiguração de vastas áreas urbanas em lugares de passagem ("não-lugares"), com repercussões sobre o efeito de memória e o sentido de lugar;

6. A globalização económica, financeira e dos modos de governação política e os seus efeitos sobre a implosão do estado-nação e a concomitante insinuação das cidades como meso-esfera de governação;

7. A globalização da cultura, associada às novas formas de afirmação contra-hegemónica de valores, identidades e comunidades locais;

8. A urbanização da injustiça, como resultado da contínua privatização dos lugares e patrimónios públicos e os seus efeitos colaterais na fragilização da cidadania e na retracção generalizada para o domínio da domesticidade e dos círculos de convivialidade restrita.

Ao olhar para a cidade e a metrópole de hoje, tendo em consideração este conjunto de factores, resulta claro que eles não estão devidamente enquadrados pela sociologia urbana clássica, entendida amplamente de modo a incorporar tanto as contribuições originais do século XIX (Weber, Sombart, Simmel, etc.), como as investidas da Escola de Chicago (Park, Wirth, etc.) e mesmo as reconceptualizações do último quartel do século XX (Castells, Lefebvre, Harvey, etc.). 
Nestas circunstâncias, pode dizer-se que a sociologia urbana clássica não dispõe hoje de instrumentos analíticos, teóricos e interpretativos capazes de escrutinar e compreender cabalmente a cidade contemporânea. Tal decorrerá do facto de assentar em dois fundamentos tópicos e epistemológicos - o tempo e o espaço - que foram profundamente abalados no seu significado filosófico. Na verdade, a sociologia urbana clássica mostra-se subsidiária das epistemologias positivistas triunfalistas que subordinam a relação da cidade com as estruturas sociais a uma espécie de "ambiente externo". Este "ambiente" é definido a partir de uma concepção dupla de tempo linear e "objectivo" e de espaço cartesiano e absoluto. O tempo social encontra-se, assim, dependente de uma perspectiva newtoniana, equivalendo-se a uma invariante da vida social. É o sentido do tempo linear, do tempo como medida da duração e da sucessão regular dos factos sociais (Kern, 1983; Lash e Urry, 1994). O espaço, por seu turno, é concebido como "objecto" e "suporte" em que a acção humana se desenrola, sempre de modo confinado e num sentido de clausura euclidiana (Emberley, 1989: 745). É a concepção de espaço como "arena" passiva, susceptível de ser visualizada e cartografada, de modo inerte, fixo e não-dialéctico (Soja, 1989; Massey, 1992).

Estas perspectivas absolutas e objectivas do tempo e do espaço são, evidentemente, constitutivas do próprio pensamento da modernidade. Analistas (das vicissitudes) da ciência e (das incompletudes) das promessas sociais da modernidade, como Boaventura de Sousa Santos (1995, 2000), Bruno Latour (1987) ou John Urry (2000a, 2000b), entre outros, partindo embora de pressupostos diversos, parecem concordar em que uma e outra - ciência e sociedade - não podem hoje ser tratadas como se enclausuradas num quadro rígido espácio-temporal, absoluto e universal, dentro do qual a vida social se desenrola. Esta crítica implica uma alteração das concepções de tempo e de espaço da modernidade e a reconceptualização destas dimensões como constituindo elas próprias acções humanas relevantes.

Estou, portanto, a reclamar uma mudança epistémica e uma transição paradigmática a operar no domínio do conhecimento sociológico sobre a cidade. ${ }^{5}$ Uma alteração dos seus fundamentos epistemológicos e dos seus

\footnotetext{
${ }^{5}$ Uma boa forma de dar conta do anquilosamento teórico da sociologia urbana clássica reside em apontar o seu culto do "sociologismo", ou seja o seu fechamento disciplinar e sua defesa da tradição. O que caracteriza este "sociologismo" é sustentar e fazer crer que tudo o que é novo e desafia o nosso conhecimento não passa de manifestação espúria de algo que já nos é familiar. A análise da cidade contemporânea feita com base na sua condição "pós-industrial", ou no paradigma de Castells (1984), a seu tempo inovador dos movimentos sociais radicais e nos consumos colectivos, por exemplo, ilustram bem este fechamento à rectaguarda da sociologia urbana. Outro exemplo é a tentativa de neutralização do lugar do espaço na análise e no discurso sociológicos sobre o urbano, como faz Saunders (1980), que assim contribui para a retradicionalização da disciplina.
} 
instrumentos teóricos, analíticos e processuais. Numa palavra, a reforma da sociologia urbana que advogo, de modo a torná-la capaz de oferecer guiões para a acção dos "construtores" da cidade das próximas décadas, implica uma capacidade para inverter os sentidos da leitura sociológica da cidade e passar a lê-la também de "baixo para cima" e "das margens para o centro".

Ser capaz de ler sociologicamente a cidade do avesso é sustentar que, com o cultural turn dos anos 80 (Chaney, 1994), o velho grito de Lefebvre sobre o "direito à cidade" está hoje assegurado. Mas é incompleto e é preciso dar-lhe consistência e juntar-lhe o direito à diferença. É aceitar que, em democracia, a cidade concede liberdade. Mas que é preciso juntar-lhe criatividade. É defender que a política está presente na cidade, mas que é preciso reinventá-la para a aproximar da velha e abstracta polis, da participação cívica e da garantia dos direitos de cidadania. É admitir que, além da sua forma, da sua estética, do seu uso e função, a arquitectura deve também re-imaginar-se na sua relação com o espaço, o tempo, os sentidos e as pulsões da cidade. É indispensável reconhecer que nem o espaço é monolítico nem o tempo absoluto e linear. Por estas razões, ler sociologicamente a cidade de "baixo para cima" e "das margens para o centro" é, numa palavra, reinventar o sentido do acto e do espaço público, participado e democrático. É imaginar a conjugação da cidade com a "não"-cidade e ousar vivê-la.

\section{Um pressuposto, quatro hipóteses e outra interrogação sobre os espaços públicos das cidades}

Perante as transformações socioeconómicas assinaladas desde os tempos da cidade da era moderna e industrial até aos nossos dias e perante o imperativo científico e social de uma visão sociológica renovada, viro-me agora, mais em concreto, para a questão dos espaços públicos urbanos. Faço-o partindo de um pressuposto, enunciando um conjunto de quatro hipóteses e, por fim, formulando uma interrogação.

\section{O pressuposto, ou a retracção do espaço público urbano ${ }^{6}$}

O pressuposto é o da chamada "crise" do espaço público das cidades, sobejamente analisado (maxime Sennett, 1978; Light e Smith, 1988; Chambers, 1990; Sorkin, 1992; Weintraub e Kumar, 1997; Jacobs, 2000). Em

\footnotetext{
${ }^{6}$ Convém esclarecer que a noção de espaço público que aqui utilizo não é coincidente nem com a "esfera pública" de Habermas, entendida como comunidade interpretativa, racional e crítica, constitutiva da ordem burguesa (Habermas, 1989), nem com os ambientes e lugares honoríficos em que, até ao século XVIII, se celebrava o poder dos reis ou da aristocracia e se evocava a sua
} 
regra, esta "crise" é vista como resultante da lógica cultural contemporânea que acentua, de um lado, o reino do individualismo e da domesticidade e, de outro lado, a cultura do movimento e da velocidade que, aplicada à técnica urbanística, organiza a cidade de acordo com o princípio geral de que os sujeitos se encontram em contínuo trânsito entre lugares (Sheller e Urry, 2000).

Em Portugal, esta "crise" do espaço público das cidades pode ser ilustrada com recurso aos contornos da participação social, cívica e cultural dos portugueses pós-1974 e, mais concretamente, através do que podemos designar por ciclos de governação política das cidades, organizados em função da vitalidade da sociedade civil e da capacidade de regulação estatal (Fortuna e Silva, 2001).

O primeiro ciclo de governação política das cidades é o ciclo da espontaneidade da sociedade civil, durante o chamado período revolucionário (1974-76), quando as ruas, praças, cafés e outros recintos se constituíram em cenários de entusiásticas manifestações públicas de indivíduos, grupos e movimentos sociais. Nesse processo, aqueles recintos públicos foram apropriados culturalmente e sujeitos a novas leituras e códigos de interpretação simbólica. "Participar" era a palavra de ordem mais mobilizadora, que continha uma carga simbólica muito particular: a de estar na rua, em grupo, soltando gestos e opiniões sobre a vida pública.

O segundo ciclo de governação é o ciclo da institucionalização da vida política, centrado em matérias de natureza política e socioeconómica formal. É a fase da recomposição política do Estado (década de 80), que amorteceu o ímpeto anterior da sociedade civil. O papel institucionalizador de "legisladores e intérpretes" (Bauman, 1987) foi essencial para a constituição do que Boaventura de Sousa Santos designou por "sociedade civil secundária" (Santos, 1990). A adesão de Portugal à União Europeia em 1986 viria a codificar os termos da discussão política que foi sendo canalizada para o domínio do desenvolvimento socioeconómico e de infra-estruturação do país. A esfera cultural permanecia remetida a um plano secundário.

O terceiro ciclo de governação é o ciclo da europeização. Estamos hoje a vivê-lo e corresponde a uma estratégia de modernização do país e das cidades por intermédio da cultura. Reduzida a preocupação com a infra-estruturação

soberania (Sennett, 1978; Boyer, 1994; Hetherington, 1998). Refiro-me ao espaço público urbano para significar os contextos físico-espaciais de localização das sociabilidades, cujos arquétipos principais são a rua e a praça pública. No entanto, uma análise sociológica mais fina aconselha a desagregar estes espaços de sociabilidade e convivialidade em pelo menos quatro categorias de espaços públicos: os marcadamente comerciais, os histórico-monumentais, os grandes equipamentos e os espaços da realização de eventos culturais efémeros (Fortuna, Abreu e Ferreira, 1999). 
do país, o papel político do Estado e das autarquias ganha relevo e a cultura é potenciada nesta fase de compaginação de Portugal com padrões económicos, educativos e culturais europeus. ${ }^{7}$ A participação pública dos cidadãos, grupos e movimentos sociais surge condicionada e, perante os efeitos sensíveis da globalização da economia, da cultura e da comunicação, o espaço público das cidades surge pautado pelos desígnios da massificação e da estetização dos consumos, do mesmo modo que o planeamento urbano e mesmo numerosas imagens identitárias e promocionais das cidades passam a sujeitar-se à lógica do mercado. ${ }^{8}$ É a chamada colonização do espaço público urbano.

Neste período, tornou-se notória uma nova orientação política relativamente à cultura como estratégia de renovação das economias locais urbanas (lazer, turismo, media e outras "industrias culturais"), que evidencia também maior envolvimento e participação cultural, como forma de integrar sectores sociais jovens ou menos qualificados, ao lado da criação de infra-estruturas, equipamentos e competências culturais novas. ${ }^{9}$

Estas novas acções culturais têm sido acompanhadas, em muitos casos, por processos de revitalização e recriação de espaços que estão a tornar a cidade mais legível e mais atractiva (ruas pedestres, recuperação de áreas e edifícios degradados, ocupação de casas devolutas, vida nocturna, etc.). De alguma forma, tudo se inclina agora para uma espécie de retorno ao centro

\footnotetext{
${ }^{7}$ Esta situação pode ser ilustrada com recurso a duas situações. Por um lado, através da evolução da despesa das administrações públicas (autárquica e central) com a cultura (M.L.L. dos Santos, 1998). Os dados disponíveis põem em relevo o investimento crescente das autarquias que, em 1992, terão mesmo ultrapassado os gastos da administração central com a cultura (Neves, 2000). Uma parte substancial deste investimento autárquico na cultura (cerca de 1/3) concentra-se em áreas "tradicionais" como o património, as publicações, os recintos e actividades socioculturais. As actividades "emergentes" como a música, as artes cénicas e plásticas, o cinema e a fotografia tendem a coincidir com as escolhas sectoriais do investimento da administração central. Por outro lado, a tendência para a "culturalização" das cidades (e do país) pode ser ilustrada pela sucessão de grandes acontecimentos culturais, com que se tem promovido a imagem internacional do país ou de cidades específicas. São exemplos destas iniciativas, entre outros, a Europália, a Lisboa'94, o Festival dos Cem Dias, a Expo'98, a Porto 2001, como de resto também a recém-enunciada intenção política de lançar um programa de Capitais Nacionais da Cultura, a ser iniciado em Coimbra, no ano de 2003.

${ }^{8}$ Para esta variedade de situações podem consultar-se os trabalhos recentemente publicados pelo Núcleo de Estudos sobre Cidades e Culturas Urbanas, do Centro de Estudos Sociais (Fortuna e Silva, 2002).

9 Desde os inícios do terceiro ciclo de governação política das cidades, tornaram-se manifestos os programas e acções estratégicas de requalificação urbana apoiados pela União Europeia para um vasto conjunto de cidades em Portugal. O conjunto destas medidas está a ser coroado pela entrada em vigor do extremamente ambicioso Programa POLIS que define como objectivos gerais a requalificação e revitalização dos centros urbanos através da promoção do que é designado por cidades verdes, digitais, do conhecimento e do entretenimento e, por último, intergeracionais.
} 
da cidade, embora um retorno de tonalidade diferente do registado no primeiro ciclo de governação enunciado.

Perante a escassez de estudos de avaliação de impactos destas políticas em Portugal, ${ }^{10} \mathrm{o}$ recurso à análise produzida sobre outras experiências semelhantes na Europa, pode levar-nos a concluir não ser líquido que este investimento seja consistente do ponto de vista social e cultural ou que produza efeitos directos e sustentados sobre as economias locais das cidades (Bianchini e Schwengel, 1990; Bianchini e Parkinson, 1993; Zukin, 1995; Matarasso, 1997; Landry, 2000; Amin et al., 2000). Quer dizer, alterar os padrões da oferta e os gostos do consumo pode não ter nada a dizer aos sectores sociais mais frágeis (famílias operárias, desempregados, idosos e reformados, grupos marginais ou lateralizados, incluindo grupos étnicos) cujos consumos, como sabemos, permanecem baixos e as suas formas de expressão política pública limitadas.

Esta diversidade de situações e níveis desiguais de envolvimento e benefício das novas políticas culturais tornam claras as dificuldades de instituir acções socialmente abrangentes de redesenvolvimento cultural das cidades. A razão de fundo desta dificuldade reside na própria ontologia da cidade moderna, feita de fragmentações e incoerências políticas, sociais e culturais. Se é destes fragmentos que se pode constituir e revigorar a imagem cultural de uma qualquer cidade, não é menos verdade que, em tempo de globalização, de crescente competitividade intra- e inter-cidades, a identificação de uma imagem emblemática ou de uma expressão identitária revelar-se-á sempre paradoxal e pode mesmo incorrer no reforço daquelas fragmentações e incoerências. Por outras palavras, as cidades não podem ser nunca globalmente globais, nem para dentro nem para fora, porquanto a globalização virtuosa ou a hegemonização de um ou vários dos seus "fragmentos" (que assim se tornam imagem de marca local) projecta-se sempre na localização ou na subordinação de outros, sejam eles grupos ou movimentos sociais, espaços ou monumentos, linguagens, artes ou saberes, actividades ou acontecimentos. ${ }^{11}$

\footnotetext{
${ }^{10}$ Entre os estudos disponíveis sobre esta matéria, cabe assinalar os trabalhos desenvolvidos no quadro do Centro de Estudos Territoriais do ISCTE, nomeadamente os de Ferreira (1997), de Ferreira e Indovina (1999) e de Castro et al. (1997). No Centro de Estudos Sociais (Núcleo de Estudos sobre Cidades e Culturas Urbanas) está em curso um projecto de investigação sobre os "intermediários culturais" que, entre outras linhas de trabalho, se dedica ao acompanhamento do Programa POLIS que, à data, engloba acções de requalificação urbana num vasto conjunto de 25 cidades.

${ }^{11}$ É neste sentido que, de acordo com Ian Chambers, muitas cidades estão a perder centralidade cívica, pois que segmentos das suas populações se encontram, como nunca, sujeitos a catalogações ameaçadoras da sua condição e vêem-se convertidos em estigmatizantes minorias étnicas e culturais, ou em (novos) pobres, reformados, inactivos ou delinquentes urbanos (Chambers, 1990: 53).
} 
Mas a questão é ainda mais complexa se admitirmos que, além da vertical "geometria do poder" (Massey, 1993), que reparte desigualmente direitos e capacidades - a cidade vista de "cima para baixo" -, as desigualdades e as diferenças sociais e culturais nas sociedades e nas cidades de hoje organizam-se também ao longo de um eixo horizontal, igualmente fracturante - a cidade vista "do centro e das margens". Nesta perspectiva, é preciso considerar as situações em que sujeitos, grupos ou movimentos sociais se põem deliberada e assumidamente "ao lado" ou "fora" do centro, num acto de lateralização social consciente e resistente. ${ }^{12}$ "Estar na margem" significa, como diz bell hooks, ocupar "um lugar de criatividade [...] a partir do qual se constrói um outro sentido do mundo" (hooks, 1990: 153$).{ }^{13}$

Este "outro sentido do mundo" revela, na verdade, uma cidadania disputada, de resistência, oposta à "estética do desaparecimento" de que fala Paul Virilio (1989). Mais do que um jogo de dualidades, este é um jogo de recombinações de referências, estilos de vida e práticas sociais que conduz à experiência de incoerência e diversidade culturais como condição urbana e, logo também, como imperativo imposto a uma renovada análise sociológica.

12 O uso da expressão "lateralização social" não rejeita e contém mesmo uma relação de poder e de "subordinação" política como a que Doreen Massey (1993) assinala, embora com estratégias de acção totalmente diversas porque fundadas noutras capacidades dos agentes sociais. Neste sentido, reconheço pertinência ao juízo de Alain Touraine quando se exprime dizendo que "estamos, hoje, a viver um momento de transição de uma sociedade vertical, que nos tínhamos habituado a designar por sociedade de classes, [...] para uma sociedade horizontal, em que o que importa é saber se estamos no centro ou na periferia" (Touraine, 1991: 166).

13 Este "outro sentido do mundo", enquanto lateralização social, pode ter sentidos políticos muito diversos de afirmação das identidades subalternas. Mas também sentidos estéticos. Dou dois exemplos: O primeiro diz respeito à estética decorativa alternativa das cidades, contida nos graffiti. $\mathrm{Na}$ verdade, a conotação dos graffiti com sinais identitários de grupos e (sub)culturas ameaçados está sujeita a interpretações estereotipadas de marginalidade e delinquência, na precisa medida em que a partir dos espaços e zonas pobres e marginais das cidades foram chegando aos centros residenciais mais centrais, ricos e poderosos das cidades. Fora deste espaço ideologicamente confinado, os graffiti são vistos por grupos dominantes como o "lixo" que, como assinala Mary Douglas, a cultura ocidental reconhece em qualquer "matéria fora do lugar" (Douglas, 1966: 35). Referências à cultura dos graffiti e dos graffiters nas cidades portuguesas podem encontrar-se nos textos de Filomena Marques et al. (1999) e de José Machado Pais (1993). Uma versão ilustrativa do discurso radical da intolerância policial perante os graffiti pode encontrar-se nas declarações de William Bratton - ex-comandante da polícia de Nova Iorque - aquando da sua visita recente a Portugal (Expresso, 28/10/2000). O segundo exemplo retiro-o do rap e da cultura hip-hop que, em Portugal, ganhou projecção, sobretudo a partir das periferias de Lisboa, através de nomes como AC, General D, Pac Man, Da Weasel, Black Company, Bantú e outros. A estética do seu "sentido do mundo" tende a ser tão política como artística e oferecer, num ou outro caso, recursos narrativos e simbólicos da identidade lateralizada e resistente, tema cuja relevância pode ser analisada mais de perto através do estudo recente de António Contador (2001). 


\section{Quatros hipóteses, ou sobre a hibridação da cultura urbana}

As recombinações a que acabo de aludir implicam reconhecer que a sociedade e a cultura, mais do que apenas compósitas, são de uma plasticidade enorme. Disse acima que nem o espaço é monolítico nem o tempo é linear e que, por isso, nos encontramos hoje perante a necessidade de revisão dos nossos instrumentos teóricos e analíticos. Em manifesta oposição à estratégia modernista de classificação racional (Zerubavel, 1991) as leituras binárias da realidade tornaram-se inaptas e sem poder explicativo, num quadro de excesso e de volatilidade dos significados das coisas e dos lugares. A alternativa tem sido a valorização da metáfora da hibridação, que enuncia o princípio da mobilidade dos elementos e da permissividade das fronteiras, bem visível em tempos de globalização (Featherstone et al., 1995; Canclini, 1989). Os objectos e as situações híbridas revelam sempre, ainda que em graus variáveis, os antecedentes naturais ou culturais das partes que neles se combinam. Na investigação académica, o corolário desta situação tem sido a gradual autonomização dos processos e mecanismos de intermediação, as suas zonas de contacto, em detrimento dos próprios elementos bem delimitados que nelas confluem e se contaminam mutuamente (Rosaldo, 1997). ${ }^{14}$

Aplicada ao estudo das cidades e dos seus espaços públicos, esta sugestão de procurar maior inteligibilidade nas zonas de contágio entre campos complexos de acção, conduz-me a sintetizar, a partir de texto recente (Fortuna e Silva, 2001), alguns possíveis desfechos para a compreensão dos espaços públicos urbanos, se perspectivados de acordo com aquilo que designo por zonas de intermediação cultural.

Admito que possamos identificar quatro zonas de intermediação principais. A primeira diz respeito às chamadas "terceiras culturas".

\footnotetext{
${ }^{14}$ Em Culture and Truth, Renato Rosaldo sustenta que esta autonomia da zona de contacto nos obriga a conceder uma atenção renovada ao que antes era tido como "espaço vazio" e de invisibilidade cultural (Rosaldo, 1989: 208). Uma boa ilustração desta reconfiguração paradigmática da investigação no domínio da história das culturas encontra-se sintetizada na literatura sobre as diásporas, em que, entre outros, se destaca o trabalho de Paul Gilroy que sugere mesmo aos historiadores da cultura que tomem "o Atlântico como uma unidade de análise singular" (Gilroy, 1993: 15), em vez de se fixarem em perspectivas analíticas absolutas. É manifesta a ressonância do trabalho de Fernand Braudel (1984) sobre o Mediterrâneo, enquanto plataforma de intermediação política, económica e geográfica entre civilizações diferentes. Reconheço que esta problemática tem ganho maior relevo quer nos chamados estudos literários e culturais comparados, quer no domínio da antropologia e etnologia. No entanto, a própria sociologia tem recebido recentes re-interpretações de sinal semelhante, nomeadamente por parte da etnometodologia (Harold Garfinkel, Harvey Sacks, Aaron Cicourel), mas também do Birmingham Centre for Contemporary Cultural Studies (Stuart Hall e Paul Willis).
} 


\section{Zona de Intermediação 1: Terceiras Culturas}

As terceiras culturas referem-se ao território transnacional de negociação e resolução de problemas e conflitos decorrentes do contacto intercultural (Featherstone, 1997). Os seus protagonistas, ao actuarem no campo da retradução e acomodação dos sentidos e significados da cultura local e global, remetem-nos para um universo de referências cosmopolitas. Detentores de competências técnicas e culturais específicas, os profissionais das terceiras culturas, se, por um lado, podem constituir-se em agentes de actualização da cultura local, por outro, podem fazer perigar a sua autenticidade, em virtude da supremacia e controlo que exercem sobre os sistemas de significação e de intencionalidade cultural. ${ }^{15}$

A hipótese que gostaria de colocar diz respeito ao eventual potencial progressista das terceiras culturas e dos seus profissionais. Um exemplo desse potencial pode retirar-se do papel comunicacional actual das novas tecnologias de comunicação (McBeath e Webb, 1997) que, no limite, podem estar a fazer emergir um novo ethos cosmopolita (Shields, 1997). Sendo certo que este ethos tanto pode actuar no sentido do reforço da ordem institucional global, como se lhe pode opor, gostaria de assinalar a possibilidade de este ethos emergente produzir efeitos significativos no relacionamento entre lugares e grupos sociais que, até há pouco, se conheciam apenas através de conotações simbólicas de oposição e distância, do género nós e outros. Ao potenciar a aproximação entre entidades distantes e opostas, as terceiras culturas e o possível ethos em emergência podem converter-se em agentes da revitalização dos espaços e dos encontros públicos das cidades. $\mathrm{O}$ requisito de base para que a hipótese frutifique é que o encontro de posições, discursos e narrativas dissonantes accione códigos alternativos e linguagens solidaristas que capacitem os sujeitos para o diálogo com a diversidade cultural e a alteridade. Por outras palavras, é essencial que esta expressão das terceiras culturas e o novo ethos reconfigurem a base elitista e segregadora, que tem dominado os contactos entre culturas (Santos, 1995, 2000; Hannerz, 1996).

15 Vejam-se, por exemplo, as intervenções estéticas e artísticas a cargo de especialistas da arquitectura e do urbanismo e a exclusão dos não-especialistas da sua apreciação ou contestação (Miles, 1997: 131). Mesmo quando justificadas formalmente com base na funcionalidade da cidade, da intencionalidade dos edifícios, ou da promoção da "transparência" e "abertura" dos espaços, não deixam de revelar um sentido de autoridade decorrente do monopólio de expertise dos seus mentores (Brain, 1997). 


\section{Zona de Intermediação 2: Relações sociais de estranhamento e tolerância}

Que os profissionais cosmopolitas das terceiras culturas possam ser equiparados à figura sociológica do estranho é a minha segunda hipótese de trabalho. A presença do estranho anula a eficácia dos nossos juízos e preconceitos, pois que é uma categoria terceira, desafiadora dos esquemas classificatórios elementares por se situar algures entre o amigo, ou o conhecido, de um lado, e o inimigo, ou o opositor, do outro. Imaginamos saber como reconhecer e o que esperar de uns e de outros. Mas não sabemos como lidar com o estranho - essa espécie de personificação da imprevisibilidade que, presente desde sempre no espaço público das cidades (Simmel, 1997a; Wirth, 1997; Park, 1967; Jacobs, 2000; Sennett, 1978; Lofland, 1998) não deixa, contudo, de surpreender o nosso quotidiano citadino. Tal como no caso das relações de anonimato, também o contacto fortuito e ocasional com o estranho poderá alimentar formas novas de sociabilidade e associação cívica desde que alicerçado numa noção nova de tolerância social, que supere a tolerância negativa, sinónimo de descomprometimento e de "indiferença civil” (Goffman, 1963), segregadora e subordinante. Ao contrário, de uma tolerância positiva que promova o (re)conhecimento do estranho poderá brotar a disponibilidade dos sujeitos e grupos para negociarem, de modo autónomo e no respeito por aquilo que os diferencia, as condições de maior equidade social e de juízo sobre a sua condição e a sua individualidade. ${ }^{16} \mathrm{O}$ requisito de base para que esta hipótese se concretize é que sejam aspectos relevantes para a vida social aquilo sobre que, numa relação social de estranhamento, os indivíduos e grupos são chamados a negociar.

\section{Zona de Intermediação 3: Domesticidade e práticas socioculturais}

Como já sustentei noutro lugar, o confronto com a alteridade é sempre interpelante. Ao invés, a exclusão desse confronto e o refúgio no isolamento doméstico impedem a construção de uma linguagem do bem-comum (Fortuna, 1999). Vale a pena reflectir acerca da função da casa, sobejamente apontada como um dos responsáveis pela atrofia e crise do espaço público. ${ }^{17}$ Desejo enunciar apenas a hipótese geral da relação

\footnotetext{
${ }^{16}$ Boaventura de Sousa Santos, embora num outro registo temático de discussão, elabora uma fórmula igualmente reveladora do que pode ser uma prática solidária como forma de conhecimento em condições de relacionamento intercultural: "é o reconhecimento do outro como igual, sempre que a diferença lhe acarreta inferioridade, e como diferente, sempre que a igualdade lhe ponha em risco a identidade" (Santos, 2000: 228).

${ }_{17}$ No domínio da teoria, é conhecida a função do espaço doméstico enquanto garante da reflexidade pessoal e condição para que os indivíduos regressem ao domínio público e sejam sociáveis. Recorde-se, a este propósito, o risco de desequilíbrio psíquico e emocional que, no entender de Simmel, os indivíduos corriam de permanecer no espaço público da metrópole, sem capacidade de recuo na
} 
do espaço privado, doméstico e familiar com o espaço público, à luz das influências da globalização da cultura e do desenvolvimento das tecnologias. A técnica de miniaturização, da portabilidade dos equipamentos, e a própria lógica do mercado (preços e sistemas de crédito) permitem sustentar que as residências particulares estão a tornar-se auto-suficientes, nomeadamente no que diz respeito ao acesso a sons, imagens, à informação e à comunicação em geral (Benko, 1997). Neste sentido, e contra a convenção sociológica, a casa pode ser vista como um espaço de abertura activa (e não apenas de passiva receptividade) a tudo o que se passa no mundo. Paralelamente, é também conhecida a tendência crescente para a multifuncionalidade das residências particulares, nomeadamente em vista das novas modalidades de trabalho flexível - teletrabalho e trabalho independente (Rochefort, 1997). Do uso, a um tempo privado e profissional, da casa tem resultado o aumento da área média dos apartamentos, bem como a subdivisão e especialização dos seus espaços interiores (Rochefort: 80-93; Lopes, 2000).

Deste modo, a casa, tal como o espaço público, está a tornar-se um espaço "colonizado" por um conjunto de agentes e instituições que lhe são exteriores. O efeito mais imediato desta "colonização" é a sua progressiva fragmentação em cada vez mais recônditos espaços de privacidade intra-familiar.

A minha hipótese, compartilhando aliás a interpretação de Daniel Vidal (1996), é, portanto, a da implosão do espaço privado. De arena familiar compartilhada, o espaço da casa está a ser estilhaçado. Como uma câmara de ressonância, está a acomodar no seu seio os mesmos sinais de agressividade, dissonância e fractura social e intergeracional que germinam no quotidiano público da cidade. O relevo da minha hipótese sobre a relação da privacidade do lar com o espaço público é, deste modo, o conselho para que olhemos para a cidade a partir da porosidade das fronteiras entre os domínios público e privado. Não podemos continuar a aceitar quaisquer definições nominalistas dos espaços, senão de forma operativa, porquanto eles se influenciam e contaminam reciprocamente a cada instante. Mas o

esfera da privacidade: "Se aos incessantes contactos públicos das pessoas nas grandes cidades" - afirma Simmel - "correspondessem as mesmas reacções interiores dos contactos que têm lugar na pequena localidade, [...] estaríamos completamente atomizados interiormente e cairíamos numa condição mental deplorável" (Simmel, 1997a: 36). A mesma linha de raciocínio surge em Sennett: "os seres humanos necessitam de criar uma certa distância face à observação íntima, feita por outros, de modo a poderem sentir-se sociáveis" (Sennett, 1978: 15). No domínio empírico das práticas e consumos culturais da população portuguesa, por exemplo, é conhecida a centralidade do espaço doméstico e o diminuto consumo cultural em espaços exo-domiciliários (Fortuna e Abreu, 2001). 
desafio para os nossos esquemas mentais e operativos, para nada dizer da nossa própria estabilidade emocional, decorrente desta porosidade das fronteiras não é de todo um desafio menor.

\section{Zona de Intermediação 4: Espaços sociais de proximidade relacional}

A minha quarta hipótese decorre daqui. Viver em situações que não são nem as situações típicas do espaço público (que retrocede e vê continuamente alterada a sua natureza - o meu pressuposto inicial) nem do espaço privado (que implode ao mesmo tempo que se mundializa a cada instante a minha terceira hipótese de trabalho) gera inseguranças, não apenas físicas, mas também mentais e ontológicas. Como poderemos, assim, viver em fronteira, delimitá-la e dar-lhe sentido de lugar? A fronteira é sempre um outro espaço e, como tal, só podemos habitá-lo de forma imaginada. A partir de posições imaginadas de poder ou de não-poder, como a partir de posições imaginadas do centro ou da periferia e das margens. A hipótese que quero desenvolver diz respeito ao que designo espaços sociais de proximidade relacional que são, portanto, espaços de imaginação e produção pessoal e colectiva, como, por exemplo e entre outros, os espaços da nossa memória identitária como os complexos históricos e monumentais das nossas cidades. São espaços orgânicos, com uma forte estrutura e espessura simbólica. Esta espessura, como tudo o que é sólido, ameaça hoje dissolver-se... não no ar, mas na lógica da objectivação e do mercado. Como outros espaços - residenciais ou de comércio e consumo - também estes complexos histórico-monumentais se encontram em vias de serem hegemonizados pelos princípios ordenadores do mercado e, nesse sentido, de promoverem contextos em que os sujeitos se vêem arrastados para uma condição alienante e atomizada.

O que está em causa é a necessidade de se pensar, sem rodeios nem nostalgias, em como confrontar esta lógica de mercadorização dos espaços públicos, históricos e monumentais, com outras lógicas, nomeadamente a do espírito de comunidade e associação, das relações de afectividade e do espírito de lugar, dos objectivos de encontro, festa e entretenimento, ou mesmo as estratégias de emblematização das identidades (Fortuna e Peixoto, 2002). Como será possível redinamizar esses espaços perante a ameaça de dissolução deslizante do seu significado e incorporá-los de modo significativo numa acção de redesenvolvimento cultural das cidades, reaproximando entre si a urbe e a polis? Da resposta que dermos resultará ou não a clareza e o sentido da fronteira em que estamos condenados a viver. Necessitamos, para tanto, de assegurar um requisito fundamental: é preciso que o redesenvolvimento cultural das cidades e dos seus espaços resulte de uma 
conferência alargada de consenso participado que se debruce sobre o lugar e o significado do tempo e do espaço na cidade, para o que se torna essencial pôr em confronto as visões díspares do que antes designei por cidade e "não"-cidade e as suas respectivas leituras e sentidos desta relação espácio-temporal. Se esta é a hipótese, a contra-hipótese traduz-se no facto de, perante a impossibilidade desta conferência de consenso, a cidade, em vez de diversa, permanecer sujeita a intervenções medíocres, ou à arrogância e à insensibilidade de muitos profissionais das terceiras culturas, ou ao utilitarismo de muitos investimentos e usos dos seus espaços públicos. Ou mesmo a tudo isso simultaneamente.

\section{A interrogação, ou sobre a beleza dos espaços públicos}

A interrogação que me inquieta respeita aos critérios estéticos dos espaços públicos da cidade. Se, como exercício académico, tivesse que apontar os responsáveis principais pela estética actual dos espaços públicos urbanos assinalaria, entre outros, naturalmente, arquitectos e urbanistas. Não sendo a cidade um produto exclusivo seu, todavia, pode afirmar-se que ambos surgem como, ou julgam ser, os negociadores, por excelência, da sua criação e reforma e, assim, da sua linguagem e significado estéticos. Não raramente, a arquitectura e a técnica urbanística são praticadas e compreendidas como actividade intelectual, estética e artística dependente de sofisticados sistemas de perícia, qualificação e gosto pessoal (Borden et al., 2001). Mesmo quando justificadas formalmente, com base na funcionalidade da cidade, na intencionalidade dos edifícios, ou na promoção da "transparência" e "abertura" dos espaços, as acções dos seus praticantes não deixam de revelar um sentido de autoridade decorrente do monopólio de expertise que, em regra, exclui a intervenção e a avaliação dos não-especialistas, remetidos à condição de meros utentes ou receptores de um produto final (Brain, 1997; Miles, 1997).

Da mesma maneira que Engels se referiu à "curiosa configuração da cidade" de Manchester que instigava a segregação social, ou que Mike Davis aborda a "arquitectura de fortaleza" de Los Angeles, encontramos na literatura sociológica especializada as mais diversas referências à influência negativa da arquitectura e do urbanismo sobre o espaço público. ${ }^{18} \mathrm{~A}$ prin-

${ }^{18}$ Desde a crítica a Haussman e aos planos anti-insurrecionais da renovação urbanística de Paris pós-1848, passando por Jane Jacobs e a "morte" do sentido de comunidade nas cidades americanas do século XX (Jacobs, 2000), ou por Richard Sennett e a "consciência do olhar" nova-iorquino que tudo e nada vê (Sennett, 1990), ou por Neil Smith e a denúncia dos limites dos processos de enobrecimento urbano (gentrification) (Smith, 1996), ou por Michael Sorkin e os efeitos perniciosos das novas centralidades comerciais (Sorkin, 1992), passando por todos estes, a mais concisa e 
cipal crítica que lhes é dirigida é a de terem subordinado um certo princípio social da realidade às preocupações estéticas e simbólicas - é o que Vattimo chama a produção da "nova monumentalidade". O trabalho de arquitectos e urbanistas, marcado por uma desmedida exaltação do princípio autoral, sacrifica a perspectiva de conjunto e dá primazia ao detalhe e ao ornamento. Ora, como argumentam Ernst Bloch (1988) ou Gianni Vattimo (1987), o ornamento estético e arquitectónico não obedece a critérios funcionais nem a lógicas e linguagens racionalistas. Por isso, os seus autores não podem já ser tratados, como no século XVIII, como "funcionários" contratados ao serviço de clientes nobres, ricos ou poderosos. Ao contrário, perdido este "vínculo", o arquitecto deixa de ser um representante fiel do imaginário dos poderosos e, por essa via, de uma determinada comunidade ou constelação de poder, e passa a trabalhar numa zona de intermediação delimitada pelo seu imaginário de criação e a consciência mais ou menos explícita da multiplicidade de linguagens estéticas e sociais. Neste sentido, o arquitecto constitui-se como autêntico intermediário cultural ou profissional das terceiras culturas.

Num tempo em que se multiplicam as imagens e os códigos de referência, as acções de intermediação são fundamentais e o papel dos arquitectos revela-se determinante na medida em que o pluralismo das suas perspectivas rejeita imagens ou interpretações únicas do espaço público. Quando pensadores como Walter Benjamin (1992) sustentam que é o nosso presente que ilumina e dá sentido ao nosso passado, ou quando Alois Riegl (1984) estabelece que somos nós, os sujeitos modernos, que estipulamos o sentido histórico e vernacular do "monumento" histórico, do mesmo modo que Dominique Poulot (1998) conclui que é a experiência actual vivida que define o que virá a ser o património histórico do futuro, estão todos eles a caucionar uma outra qualidade (ou será dificuldade?) da intermediação dos arquitectos: a possibilidade de a produção da "nova monumentalidade" vir a inscrever-se na cidade como sinal enraízado e duradouro da identidade e da cultura da cidade.

Se, como Halbwachs (1950) e Simmel (1997b) sustentaram com veemência, a nossa memória é tanto mais consistente quanto mais espacializada,

acutilante denúncia da retracção dos espaços públicos venho encontrá-la em Marc Wiel que, sem rodeios, declara que a desvitalização do espaço público urbano, se deve à mediocridade dos profissionais da arquitectura e ao utilitarismo dos investimentos" (Wiel, 1999). Evidentemente que é também da reflexão produzida por arquitectos e urbanistas que nos chega uma perspectiva crítica sobre os efeitos da sua acção na vida social urbana. Para dar apenas alguns exemplos desta perspectiva entre nós, vejam-se, entre outros, os trabalhos de Helena Roseta (1999), José Manuel Fernandes (1999) ou Manuel Graça Dias (2000). 
então a possibilidade de a "nova monumentalidade" vir a constituir-se em marca ou vestígio patrimonial de um determinado passado social dependerá da qualidade da realidade presente que estejamos a viver. E este não é um desafio menor imposto à obra de arquitectos e urbanistas e à filosofia da sua acção que, de acordo com vários comentadores (por exemplo, Neil Leach, 2000), corre riscos de saturação em vista do investimento excessivo na estética e na imagem dos espaços e paisagens urbanos. Arquitectos e urbanistas encontram-se, assim, obrigados à construção social de um espaço público urbano bem sucedido hoje, para que possa ser belo amanhã. Mas o que é o espaço público bem sucedido? É um espaço público que, para além do seu sentido estético, se revela inteligível, relativamente abstracto e não apenas funcional, mas, ao mesmo tempo, suficientemente definido e explícito, de modo a promover a intersubjectividade da cidade. É da espacialidade prática e tangível dos espaços públicos de hoje que se avaliará amanhã a sua beleza e o significado patrimonial da sua linguagem.

\section{Conclusão}

Admito que todas estas considerações - as minhas e as de que me fiz eco tenham por detrás um imaginado e, porventura, romanceado espaço público, enquanto espaço de co-presença, transclassista e solidarista, garante de direitos, de acesso livre e democrático, histórica e culturalmente denso. Esse era, aliás, o meu pressuposto. O referente do espaço público que hoje temos é histórica e culturalmente difuso, traduzido talvez pela representação que temos da velha urbe, da clássica polis, e da transparente ágora, onde a justiça, a coesão social, a democracia e a consciência de si se alcançam e asseguram apenas na relação directa dos sujeitos uns com os outros. A história e a política têm reservas profundas sobre a efectiva concretização deste generoso espaço público num passado mais ou menos distante. Tal não nos impede porém, de o imaginarmos como um cenário futuro que deve orientar e mobilizar o nosso presente. Um futuro que, além do mais, se precipita velozmente sobre o presente ao enunciar a duplicação da população da cidade em poucas décadas e, portanto, uma precarização ainda maior das condições de vida urbana. É preciso fazer das nossas cidades algo politicamente criativo e cultural e socialmente sustentável. O que é isto? É construir a cidade do futuro próximo como uma cidade nova. Quero dizer, construir uma cidade que corrija os principais erros da cidade de hoje e se mostre uma cidade justa, imaginativa, ecológica, tão compacta como policêntrica, com memória e sentido de lugar, de fácil contacto social, culturalmente diversa e, acima de tudo, uma cidade bela. 
Recentemente, num ensaio sobre a cidade e a globalização (Fortuna, 1997), sustentei que nunca estivemos tão perto como hoje de produzirmos um discurso renovado da cidade, nem de reconhecer que só no cruzamento de diferentes campos discursivos e tradições intelectuais poderemos reencontrá-la na plenitude da sua multivocalidade e polivalência. Argumentava então que de uma sociologia urbana clássica em perda de capacidade analítica e interpretativa, teríamos de passar a uma sociologia das cidades. Conservo esta opinião. Mais do que isso, julgo que dispomos hoje de um património de conhecimento a partir do qual se podem pensar os fundamentos dessa nova teoria sociológica da cidade contemporânea. Parte desse património de saberes tem que ser resgatada à usura sofrida com a consagração da perspectiva modernista/racionalista que assolou a sociologia urbana clássica. Desde o perspicaz Simmel (1997a) ao sofisticadíssimo Benjamin (1992), passando pelo voluntarista Lefebvre (1974) e ainda Foucault (1986). Outra parte deve permanecer activa como teste de hipóteses a sufragar. Penso em Sennett (1990), Harvey (1973, 1989), Zukin (1991, 1995) e Michel de Certeau (1980), para só nomear alguns. Outra parte ain$\mathrm{da}$, como a que ressalta dos recentes contributos oriundos das mais diversificadas áreas e perspectivas que estão a reclamar uma atitude sociológica nova sobre a cidade e a cultura urbana, terá de ser capaz de incluir "os outros lados" da condição urbana de hoje e, assim, também da cidade de amanhã.

\section{Referências Bibliográficas}

Amin, A. et al. (2000), Cities for the Many, Not for Few. Bristol: The Policy Press.

Baptista, Luís V. (1997), Crescimento urbano e migrações internas (Lisboa, 1900-1985). Arcozelo: Estratégias Criativas.

Bauman, Z. (1987), Legislators and Interpreters. Oxford: Polity Press.

Benjamin, Walter (1992), «Infância em Berlim por volta de 1900», in W. B., Rua de sentido único e infância em Berlim por volta de 1900. Lisboa: Relógio d'Água, 109-197.

Benko, G. (1997), «Introduction», in G. Benko; U. Strohmayer (orgs.), Space and Social Theory. Oxford: Blackwell, 1-44.

Bianchini, F; Parkinson, M. (1993), Cultural Policy and Urban Regeneration: The Western European Experience. Manchester/New York: Manchester UP.

Bianchini, F.; Schwengel, H. (1990), «Re-imagining the City», in John Corner; Sylvia Harvey (orgs.), Enterprise and Heritage: Cross Current at National Culture. London/ New York: Routledge, 212-234.

Bloch, E. (1988), The Utopian Function of Art and Literature. Cambridge, Mass.: The MIT Press. 
Borden, I. et al. (2001), «Things, Flows, Filters, Tactics», in I. Border et al. (orgs.), The Unknown City: Contesting Architecture and Social Space. Cambridge, Mass.: The MIT Press, 3-27.

Boyer, M. C. (1994), The City of Collective Memory. Its Historical and Architectural Entertainments. Cambridge, Mass.: The MIT Press.

Brain, D. (1997), «From Public Housing to Private Communities: The Discipline of Design and the Materialization of the Public/Private Distinction in Built Environment», in J. Weintraub; K. Kumar (orgs.), Public and Private in Thought and Practice. Chicago: The University of Chicago Press, 237-267.

Braudel, F. (1984), O Mediterrâneo e o mundo mediterrânico na época de Filipe II. Lisboa: D. Quixote.

Canclini, N. (1989), Culturas híbridas. São Paulo: Edusp.

Castells, M. (1973), La question urbaine. Paris: Maspero.

Castells, M. (1984), Problemas de investigação em sociologia urbana. Lisboa: Presença.

Castro, A. et al. (1997), «O plano de urbanização da Expo'98 e os compromissos da política urbana de Lisboa», Sociologia - Problemas e Práticas, 24, 197-209.

Chambers, I. (1990), Border Dialogues: Journeys in Postmodernity. London/New York: Routledge.

Chaney, D. (1993), Fictions of Collective Life: Public Drama in Late Modern Culture. London/New York: Routledge.

Chaney, D. (1994), The Cultural Turn: Scene-Setting Essays on Contemporary Cultural History. London: Routledge.

Contador, A. (2001), A cultura juvenil negra em Portugal. Oeiras: Celta.

Costa, A. F. (1999), A sociedade de bairro. Oeiras: Celta.

Coulanges, Fustel de (1997), La cité antique. Paris: Flammarion.

Davis, M. (1990), The City of Quartz: Escavating the Future in Los Angeles. London/ New York: Verso.

de Certeau, M. (1980), L'invention du quotidien. Paris: Gallimard.

Dias, M. G. (2000), O Homem que gostava de cidades. Lisboa: Relógio d'Água.

Douglas, M. (1966), Purity and Danger. New York: Praeger.

Emberley, P. (1989), «Places and Stories: The Challenge of Technology», Social Research, 56, 741-785.

Engels, F. (1958), The Condition of the Working Class in England. Stanford: Stanford UP.

Esperança, E. J. (1997), Património e comunicação: Políticas e práticas culturais. Lisboa: Vega.

Fainstein, S. (1999), «Can We Make the Cities We Want?», in R. Beauregard; BodyS. Gendrot, (orgs.), The Urban Moment. Thousand Oaks: Sage, 249-272.

Featherstone, M. et al. (1995), Global Modernities. London: Sage. 
Featherstone, M. (1997), «Culturas globais e culturas locais», in C. Fortuna (org.), 83-103.

Fernandes, A. T. (1999), Para uma Sociologia da Cultura. Porto: Campo das Letras.

Fernandes, J. L. L. (1998), O sitio das drogas: Etnografia das drogas numa periferia urbana. Lisboa: Editorial Notícias.

Fernandes, J. M. (1999), Cidades e Arquitecturas. Lisboa: Livros Horizonte.

Ferreira, V. M.; Indovina, F. (orgs.) (1999), A cidade da Expo'98. Lisboa: Bizâncio.

Ferreira, V. M. et al. (1997), Lisboa, a metrópole e o rio. Centralidade e requalificação das frentes de água. Lisboa: Bizâncio.

Fortuna C.; Silva, A. S. (2001), «As cidades do lado da cultura: Espacialidades sociais e modalidades de intermediação cultural», in B. S. Santos, (org.), Globalização: Fatalidade ou utopia?. Porto: Afrontamento, 407-459.

Fortuna, C. (org.) (1997), Cidade, cultura e globalização: Ensaios de sociologia. Oeiras: Celta.

Fortuna, C.; Abreu, P. (2001), «Consumos e práticas culturais: Coimbra e outras paragens», OBS - Boletim do Observatório das Actividades Culturais, 9, 8-16.

Fortuna, C.; Peixoto, P. (2002), «Recriação e reprodução de representações no processo de transformação das paisagens urbanas portuguesas», in C. Fortuna; A. S. Silva, (orgs.), 15-65.

Fortuna, C.; Silva, A. S., (orgs.) (2002), Projecto e circunstância: Culturas urbanas em Portugal. Porto: Afrontamento.

Fortuna, C. (1999), Identidades, percursos, paisagens culturais: Estudos sociológicos de cultura urbana. Oeiras: Celta.

Fortuna, C.; Ferreira, C.; Abreu, P. (1999), «Espaço público urbano e cultura em portugal», Revista Crítica de Ciências Sociais, 52/53, 85-117.

Foucault, M. (1986), «Other Spaces: The Principles of Heterotopia», Lotus International, 48-49, 9-17.

Gilroy, P. (1993), The Black Atlantic: Modernity and Double Consciousness. London: Verso.

Goffman, E. (1963), Behavior in Public Places. New York: Free Press of Glencoe.

Habermas, J. (1989), The Structural Transformation of the Public Sphere. Cambridge Mass.: The MIT Press [1962].

Halbwachs, M. (1950), La mémoire collective. Paris: PUF.

Hannerz, U. (1996), Transnational Connections. London/New York: Routledge.

Harvey, D. (1973), Social Justice and the City. Oxford: Blackwell.

Harvey, D. (1989), The Condition of Postmodernity: An Enquiry into the Origins of Cultural Change. Oxford: Blackwell.

Hetherington, K. (1998), Expressions of Identity: Space, Performance, Politics. London: Sage.

hooks, b. (1990), Yearning: Race, Gender and Cultural Politics. Boston: South End Press. 
Jacobs, J. (2000), The Death and Life of Great American Cities. London: Pimlico [1961]. Jonas, S. (1995), «La Grosstadt-métropole européenne dans la sociologie des pères fondateurs allemands», in J. Rémy (org.), George Simmel: Ville et modernité. Paris: L'Harmattan, 19-35.

Kern, S. (1983), The Culture of Time and Space, 1880-1918. Cambridge Mass.: Harvard UP.

Landry, Ch. (2000), The Creative City: A Toolkit for Urban Innovators. London: Comedia. Lash, S.; Urry, J. (1994), Economies of Signs and Space. London: Sage.

Latour, B. (1987), Science in Action: How to Follow Scientist and Engineers Through Society. Milton Keynes: Open UP.

Leach, Neil (2000), The Anaesthetics of Architecture. Cambridge, Mass.: The MIT Press.

Ledrut, R. (1968), L'espace social de la ville. Paris: Anthropos.

Lefebvre, H. (1968), Le droit à la ville. Paris: Anthropos.

Lefebvre, H. (1974), La production de l'espace. Paris: Anthropos.

Light, A.; Smith, J. M. (orgs.) (1988), The Production of Public Space. Oxford: Rowman \& Littlefield Publishers.

Lofland, L. (1998), The Public Realm: Exploring the City's Quintessential Social Territory. New York: Aldine de Gruiter.

Lopes, J. T. (2000), A cidade e a cultura: Um estudo sobre práticas culturais urbanas. Porto: Afrontamento.

Marques, F. et al. (1999), «Traços falantes: A cultura dos jovens graffiters», in José Pais Machado (org.), Traços e riscos de vida. Porto: Ambar, 175-211.

Massey, D. (1993), «Power Geometry and a Progressive Sense of Place», in J. Bird, et al. (orgs.), Mapping the Futures. London: Routledge, 59-69.

Massey, D. (1992), «Politics and Space/Time», New Left Review, 196, 65-84.

Matarasso, F. (1997), Use or Ornament: The Social Impact of Participation in the Arts. London: Comedia.

McBeath, G.; Webb, S. (1997), «Cities, Subjectivity and Cyberspace», in Sallie Westwood; John Williams (orgs.), Imagining Cities: Scripts, Signs, Memory. London/New York: Routledge, 249-260.

Miles, M. (1997), Art Space and the City: Public Art and Urban Futures. London/New York: Routledge.

Mumford, L. (1961), The City in History. New York: Harcourt Brace and World.

Neves, J. S. (2000), Despesas dos municípios com Cultura. Lisboa: Observatório das Actividades Culturais.

Pais, J. M. (1993), Culturas juvenis. Lisboa: Imprensa Nacional-Casa da Moeda.

Pais, J. M. (org.) (1999), Traços e riscos de vida. Porto: Ambar.

Park, R. (1967), «The City: Suggestions for the Investigation of Human Behavior in an Urban Environment», in R. E. Park et al. (orgs.), The City. Chicago: Chicago UP, $1-46$ [1915]. 
Pirenne, Henri (1973), As cidades da Idade Média. Mem Martins: Europa América [1925].

Poulot, D. (1998), «Le patrimoine et les aventures de la modernité», in D. P. (org.), Patrimoine et modernité. Paris: L'Harmattan, 1-67.

Rémy, J.; Voyé, L. (1994), A cidade: Rumo a uma nova definição?. Porto: Afrontamento. Riegl, A. (1984), Le culte moderne des monuments. Paris: Seuil [1903].

Rochefort, R. (1997), Le consommateur entrepreneur: Les nouveaux modes de vie. Paris: Editions Odile Jacob.

Rogers, R. (2001), Cidades para um pequeno planeta. Barcelona: Gustavo Gili.

Rosaldo, R. (1989), Culture and Truth: The Remaking of Social Analysis. Boston: Beacon Press.

Rosaldo, R. (1997), «Cultural Studies and the Disciplines», in Peter Gibian (org.), Mass Culture and Everyday Life. London/New York: Routledge, 26-33.

Roseta, H. (1999), «A cidade insustentável ou as quatro dimensões da sustentabilidade urbana», Urbanismo, 1(2), 12-22.

Salgueiro, T. B. (1999), A cidade em Portugal: Uma geografia urbana. Porto: Afrontamento.

Santos, B. S. (1990), O Estado e a sociedade em Portugal (1974-1988). Porto: Afrontamento.

Santos, B. S. (1995), Toward a New Common Sense. Law, Science and Politics in the Paradigmatic Transition. New York: Routledge.

Santos, B. S. (2000), Crítica da razão indolente: Contra o desperdício da experiência. Porto: Afrontamento.

Santos, M. L. Lima dos (org.) (1998), As políticas culturais em Portugal. Lisboa: Observatório das Actividades Culturais.

Saunders, P. (1980), Urban Politics. London: Penguin.

Sebastião, J. M. (1998), Crianças da rua: Modos de vida marginais na cidade de Lisboa. Oeiras: Celta.

Sennett, R. (1990), The Conscience of the Eye: The Design and Social Life of Cities. New York/London: Norton.

Sennett, R. (1978), The Fall of Public Man. New York: Vintage Books.

Sheller, Mimi; Urry, John (2000), «The City and the Car», International Journal of Urban and Regional Research, 24(4), 737-757.

Shields, R. (1997), «Spatial Stress and Resistance: Social Meanings of Spatialization», in G. Benko; U. Strohmayer (orgs.), Space and Social Theory. Oxford: Blackwell, 186-202.

Shields, R. (1999), Lefebvre, Love and Struggle: Spatial Dialectics. London/New York: Routledge.

Short, J. R. (1991), Imagined Country: Environment, Culture and Society. London/New York: Routledge.

Silva, A. S. et al. (2000), Públicos para a cultura na cidade do Porto. Porto: Afrontamento e CMP. 
Silvano, F. (1997), Território da identidade: Representações do espaço em Guimarães, Vizela e Santa Eulália. Oeiras: Celta.

Simmel, G. (1997a), «A metrópole e a vida do espírito», in C. Fortuna (org.), Cidade, cultura e globalização: Ensaios de sociologia. Oeiras: Celta, 31-43 [1903].

Simmel, G. (1997b), «The Sociology of Space», in D. Frisby; M. Featherstone (orgs.), Simmel on Culture. London: Sage, 137-170 [1903].

Smith, N. (1996), The New Urban Frontier: Gentrification and the Revanchist City. London/New York: Routledge.

Soja, E. (1989), Postmodern Geographies: The Reassertion of Space in Critical Theory. London: Verso.

Sombart, W. (1978), Il Capitalismo moderno. Turim: Unione Tipografico [1916].

Sorkin, M. (org.) (1992), Variations on a Theme Park: The New American City and the End of Public Space. New York: Noonday Press, 154-180.

Southall, A. (1998), The City in Time and Space. Cambridge: Cambridge UP.

Stallybrass, P.; White, A. (1986), The Politics and Poetics of Transgression. London: Methuen.

Stilgoe, J. R. (1988), Borderland: Origins of the American Suburb (1820-1939). New Haven: Yale UP.

Tönnies, Ferdinand (1972), Comunidad y Asociación. Barcelona: Ed. Península [1887].

Touraine, A. (1991), «Face à l'exclusion», in J. Baudrillard et al., Citoyenneté et urbanité. Paris: Editions Esprit, 165-173.

Toynbee, Arnold (1970), Cities on the Move. Oxford: Oxford UP.

Urry, J. (2000a), Sociology Beyond Societies: Mobilities for the Twenty-First Century. London/New York: Routledge.

Urry, J. (2000b), «O Tempo, a complexidade e o global», Boletim Informativo. Associação Portuguesa de Sociologia. Série 3, n. 4.

Vattimo, G. (1987), O fim da modernidade: Niilismo e bermenêutica na cultura pós-moderna. Lisboa: Presença.

Vidal, D. (1996), «Le territoire de l'altérité», in Sylvia Ostrowetsky (org.), Sociologues en Ville. Paris: L'Harmattan, 45-56.

Virilio, P. (1989), Esthétique de la disparition. Paris: Editions Galilée.

Weber, M. (1982), La ville. Paris: Aubier Montaigne [1921].

Weintraub, J.; Kumar K. (orgs.) (1997), Public and Private in Thought and Practice. Chicago: The University of Chicago Press.

Wiel, M. (1999), «La transition urbaine», Recherches - Revue du MAUSS, 14, 175-184.

Wirth, L. (1997), «O urbanismo como modo de vida», in C. Fortuna (org.), Cidade, cultura e globalização: Ensaios de sociologia. Oeiras: Celta, 45-65 [1938].

Zerubavel, E. (1991), The Fine Line: Making Distinction in Everyday Life. Chicago/ London, University of Chicago Press. 
Zukin, S. (1991), Landscapes of Power: From Detroit to Disneyworld. Berkeley: University of California Press.

Zukin, S. (1995), The Cultures of Cities. Cambridge, Mass./Oxford: Blackwell.

Sheller, Mimi; Urry, John (2000), «The City and the Car», International Journal of Urban and Regional Research, 24(4), 737-757. 